\title{
IoT BASED UNDERGROUND DRAINAGE MONITORING SYSTEM
}

\author{
Mr. Kamal Kumar $\mathbf{V}^{1}$, Chandhini $\mathbf{G}^{2}$, Chithra $\mathrm{B}^{3}$, Kiruthikadevi ${ }^{4}$, P Bhagyasasi ${ }^{5}$ \\ ${ }^{1}$ Department of Electrical and Electronics Engineering, Assistant Professor, KPR Institute of Engineering and Technology, \\ Coimbatore, Tamilnadu, India \\ ${ }^{2,3,4 \& 5}$ Department of Electrical and Electronics Engineering, UG Scholar, KPR Institute of Engineering and Technology, \\ Coimbatore, Tamilnadu, India \\ Email: kamalkumar.v@kpriet.ac.in ${ }^{1}$, chandhiniganesh98@gmail.com², chithrakokhilababu@gmail.com³ \\ kirthi14699@gmail.com ${ }^{4}$, bhagyadeee07@gmail.com ${ }^{5}$
}

\begin{abstract}
Underground drainage monitoring system plays an essential role in keeping the cities clean and healthy. Compared to other countries, India consists of the highest number of sewage workers. Exposure of sewage workers to poisonous gases like hydrogen sulphide, sulphur dioxide, carbon monoxide, methane, ammonia, and nitrogen oxide increases the sewage workers' death. The main aim of this project is to design a network system that helps in monitoring poisonous gases present in sewage. Whenever the gas level crosses the threshold value, the information with different gas ppm values is displayed on the smart phone through the app. It also indicates whether it is safe for the manual scavengers to work in the environment or not
\end{abstract}

Keywords-Smart phone, IOT, Alarm, Threshold value, Sensors, Application, LED, Sewage system.

\section{INTRODUCTION}

The underground drainage system monitoring plays a very important role in making the cities clean. In India, the process of monitoring and maintaining the drainage system is done manually. The drainage consists of solid and liquid waste generated by hospitals, industries, factories and homes. Hazardous gases are released from this waste, which affects human health. Exposure of sewage workers to poisonous gases increases the chances of sewage workers affected by diseases like paratyphoid fever, hepatitis and even death. Manual monitoring \& cleaning the drainage is necessary, but it leads to huge accidental deaths of human due to over gas in

\section{RELATED WORKS:}

\section{[1].SMART CITY MONITORING SYSTEM USING IOT:}

AUTHOR: Prof. S A.Shaikh 1, Sonewane.

DESCRIPTION: The smart city development system is to monitor the city's resource to manage and faster the development of cities. The main requirement is to upgrade healthy and safe cities that deliver the real-time service and facility to implement smart using IOT concept with wireless communication[1].

\section{[2]. UNDERGROUND MONITORING SYSTEM FOR CITIES USING IOT:}

Vol. 4 (6), December 2020, www.ijirase.com
Manholes. According to a recent survey, at least one worker had died while cleaning a sewage tank for every five days since the beginning of 2017. The death of sewage workers has been increasing day by day[2].

To protect the sewage worker from death, we have come up with a solution called IOT based underground drainage monitoring system that helps in monitoring hazardous gases present in sewage \& helps to alert the sewage workers whenever the gas level crosses the specified limit. It also displays the value of the gas level in the smartphone through the app. It also helps decide whether it is safe for the worker to work in the environment.

AUTHOR: Muragesh S. Yuwat.

DESCRIPTION: The IoT consists of real-life objects, communication devices attached to sensor networks, and communication between the real world and the information world. The sensor network is key for IoT. It represents the implementation and design function of underground drainage monitoring for IoT applications. The proposed model provides a system for monitoring the gas levels in the underground drainage system and monitoring the gas level's current status[3]. 


\section{PROPOSED SYSTEM}

The proposed methodology is based on IoT, which helps in monitoring the hazardous gases present in sewage. Whenever the gas level crosses the threshold value, the sewage workers are alerted through a buzzer indicating whether it is safe for the worker to work or not through an app in the smartphone. This system helps in saving the life of sewage workers[14].

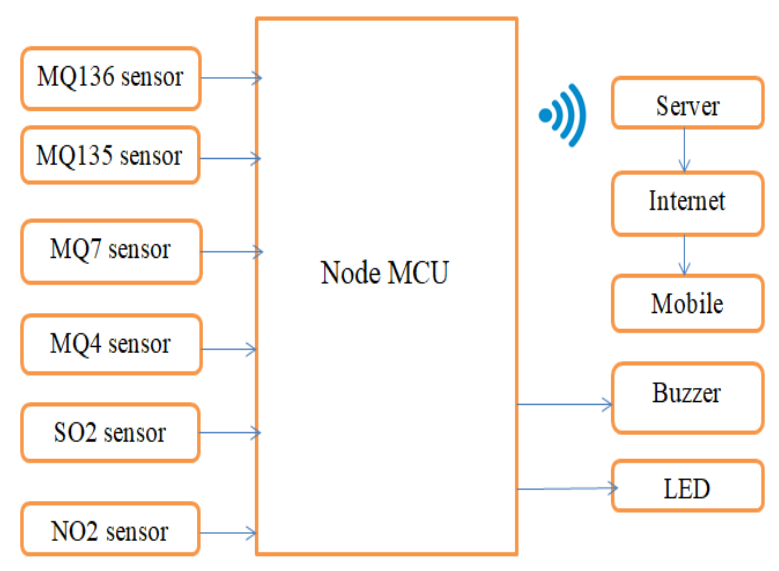

Figure1. Block Diagram

Here six gas sensors such as MQ136, MQ135, MQ4, MQ7,SO2,N02 are used for monitoring hazardous gases such as hydrogen sulphide, ammonia, methane, carbon monoxide, sulphur dioxide, nitrogen oxide. These six sensors are connected to Node MCU and the output is connected to a digital dashboard through the server and to the buzzer and LED. The six sensors used over here are used to sense the gas and sends the output to the Node MCU. The output of the Node MCU is connected to the smartphone that is an ionic application. In Node MCU, the sensors' output value is compared with threshold values and when the level goes above the specified limit it displays as danger in the smartphone. When the result is shown in the smartphone the alarm is triggered using a buzzer whereby LED also glows. The sewage worker working in the sewage is alerted, and the deaths of manual scavengers can be avoided[5].

\section{SYSTEM SPECIFICATIONS:}

\section{MQ136 SENSOR}

MQ136 gas sensor is a message queue sensor that is used to detect hydrogen sulfide gas. This gas is produced as a result of the microbial breakdown of organic material in the absence of oxygen. Hydrogen sulphide is a colourless gas with a odour of rotten eggs[6]. When Hydrogen sulphide gas concentration goes above $50 \mathrm{ppm}$, it leads to irritation of Vol. 4 (6), December 2020, www.ijirase.com eyes, nausea, headache \& exposure to high level leads to rapid unconsciousness, coma $\&$ death.

\section{MQ135 SENSOR}

MQ135 gas sensor is used to detect gases like NH3, NOx, Alcohol, Benzene, Smoke and CO2. Its detection range is 10 to $50 \mathrm{ppm}$ for $\mathrm{NH} 3,10$ to $50 \mathrm{ppm}$ for benzene, 10 to 50 for alcohol. It is mainly used for air quality monitoring applications and is also used for domestic \&industrial purposes. Its operating voltage is $+5 \mathrm{~V}$. Exposure to MQ135 sensor irritates the respiratory system, eyes, nose \& throat. It also causes lung damage and can result in blindness[7].

\section{MQ7 SENSOR}

MQ7 gas sensor is used to detect carbon monoxide gas. The detection range of carbon monoxide gas ranges from 20$2000 \mathrm{ppm}$. If carbon monoxide levels are high, the person may become unconscious or die. Exposure to a moderate level of this gas also increases the risk of heart disease[8].

\section{MQ4 SENSOR}

MQ4 gas sensor is used to detect methane gas. The detection range of methane gas ranges from 300-10,000 ppm. This sensor is susceptible to methane and natural gas. Exposure to high levels of methane can result in nausea, memory loss and loss of consciousness[9].

\section{SO2 SENSOR}

$\mathrm{SO} 2$ sensor is used to detect the concentration of sulphur dioxide gas. It is a toxic gas that leads to many health problems. Its detection range is $0-2000 \mathrm{ppm}$. It is a toxic gas that affects the respiratory system, particularly lung function. It causes coughing and leads to asthma and chronic bronchitis.

\section{NO2 SENSOR}

$\mathrm{NO} 2$ gas sensor is used to detect nitrogen dioxide gas. Its detection range is $5-10 \mathrm{ppm}$. This is one of the most dangerous gases which can seriously damage the respiratory system with a very low concentration. It can also lead to nausea, irritation in the eyes.

\section{NODE MCU}

The Node MCU (node microcontroller) is an open-source hardware and software. The software is built around a system on a chip (SOC) called the ESP8266 and hardware based on ESP12 module, scripting languages Lua is used. The ESP8266 node MCU has total 17 General Purpose I/O 
Pins. Node MCU has inbuilt-Fi, more GPIOs and supports Bluetooth 4.2. It is very cheap when to compare to Arduino UNO. Node MCU is the heart of the proposed system, which controls the entire process[10].

\section{IV.RESULTS \& DISCUSSION}

An ionic app is developed to display the amount of gas levels individually to the sewage workers. When the gas level crosses the threshold value, the buzzer makes a sound alerting the sewage worker. This system prevents the death of sewage workers. Below two cases are mentioned for a clear understanding of the working of the ionic application.

\section{CASE 1}

In case 1 all the gas levels are below the threshold values so the buzzer will not make a sound $\&$ the led does not glow.

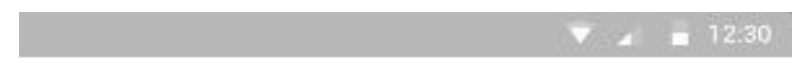

\section{SMART DRAINAGE MONIT...}

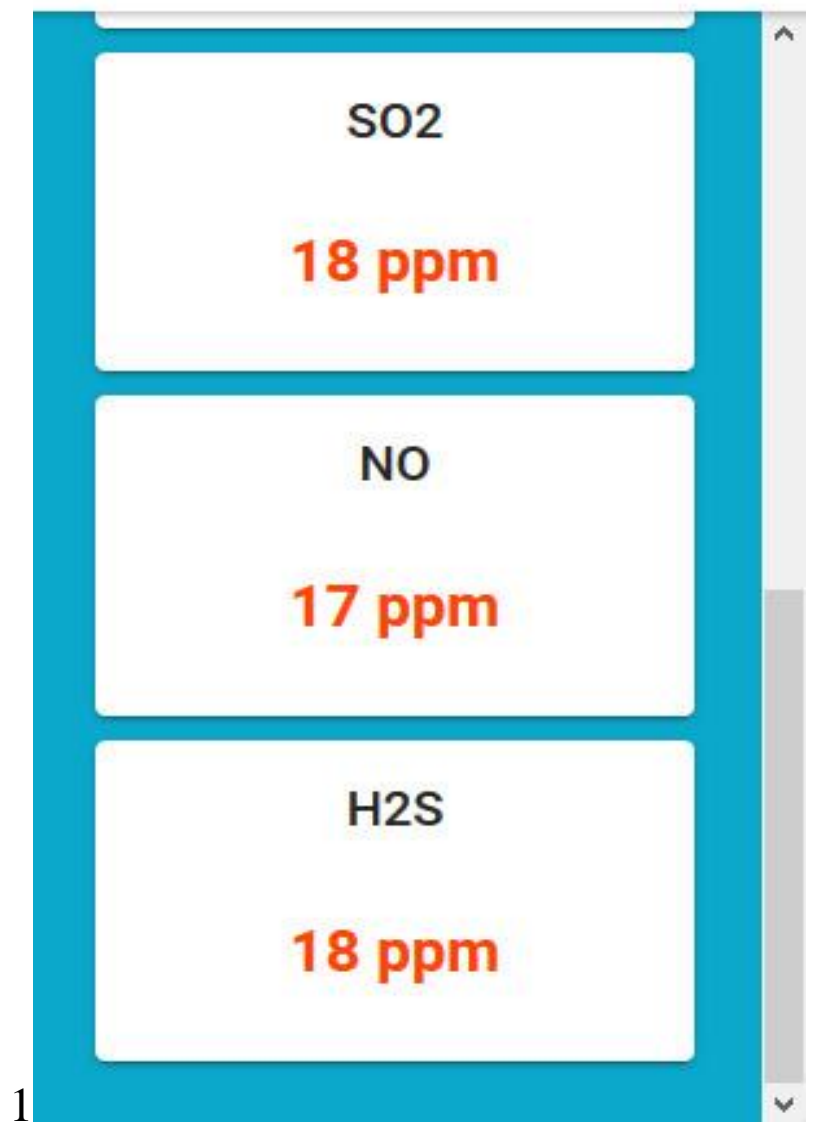

Figure 2. Software Output(Case 1)

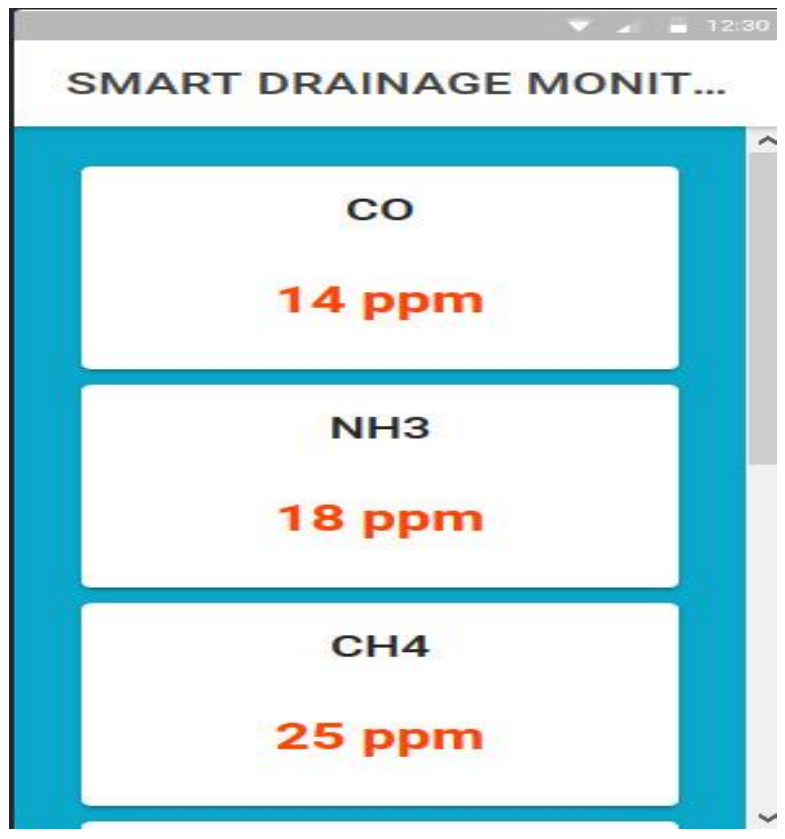

Figure 3. Software Output (Case 1)

\section{CASE 2}

In case 2, the Carbon monoxide gas is above the threshold value so the buzzer makes a sound \& led glows, indicating it is not safe for the sewage worker to work over there. By following this method, the death of sewage workers can be avoided.

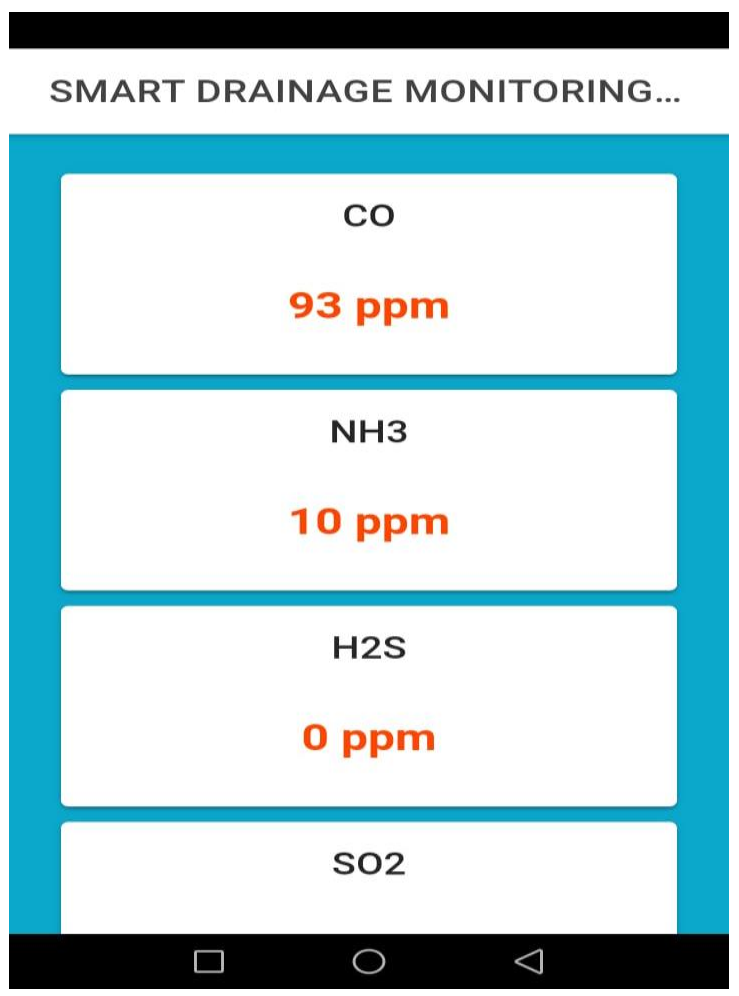

Figure 4. Software Output (Case 2) 


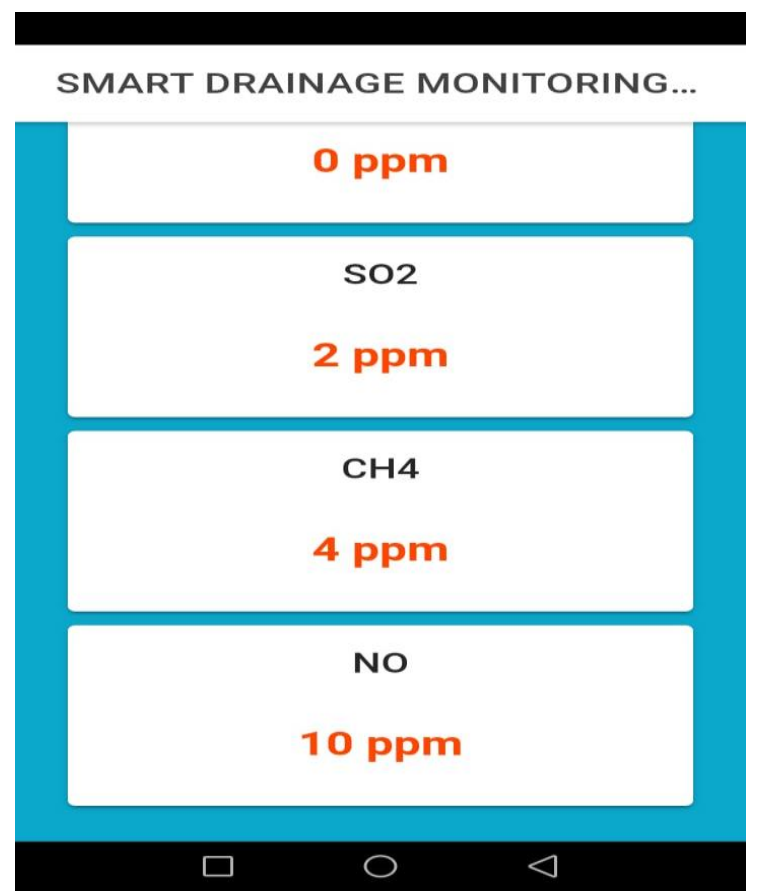

Figure 5. Software Output (Case 2)

\section{CONCLUSION:}

This project provides a smart solution to monitor the toxic gases present in sewage and alert the manual scavengers when the level goes above the specified limit. Here six sensors are used to detect the gases, and the MCU's heart is the heart of the system that controls the entire system. Node MCU consists of an inbuilt $\mathrm{Wi}-\mathrm{Fi}$, which connects the whole process to the internet and the output is displayed in the smartphone through the app. The smart drainage monitoring system helps people move to safer areas when the gas level is above the specified limit. This system helps to reduce the death of sewage workers and it also has the advantage of monitoring the amount of pollution on their mobile phones using the application.

\section{REFERENCES:}

[1] S. A. Shaikhl, Suvarna A. Sonawane, "Monitoring Smart City Application Using Node MCU on IOT" International Journal of Innovative science, Engineering and Technology, Vol 5 Issue VIL, July 2017.

[2] Muragesh, S. K., \& Rao, S. (2014). Automated internet of things for underground drainage and manhole monitoring system for metropolitan cities. International Journal of Information \& Computation Technology, 4(12).

[3] Lazarescu, M. T. (2013). Design of a WSN platform for longterm environmental monitoring for IoT applications. IEEE Journal on emerging and selected topics in circuits and systems, 3(1), 45-54.

[4] Zhou, J., Leppanen, T., Harjula, E., Ylianttila, M., Ojala, T., Yu, C., ... \& Yang, L. T. (2013, June). Cloudthings: A common architecture for integrating the internet of things with cloud computing. In Proceedings of the 2013 IEEE 17th

Vol. 4 (6), December 2020, www.ijirase.com
International Conference on Computer Supported Cooperative Work in Design (CSCWD) (pp. 651-657). IEEE.

[5] Manna, S., Bhunia, S. S., \& Mukherjee, N. (2014, May). Vehicular pollution monitoring using IoT. In International Conference on Recent Advances and Innovations in Engineering (ICRAIE-2014) (pp. 1-5). IEEE.

[6] Gopavanitha, K., \& Nagaraju, S. (2017, August). A low cost system for real time water quality monitoring and controlling using IoT. In 2017 International Conference on Energy, Communication, Data Analytics and Soft Computing (ICECDS) (pp. 3227-3229). IEEE.

[7] Keshamoni, K., \& Hemanth, S. (2017, January). Smart gas level monitoring, booking \& gas leakage detector over iot. In 2017 IEEE 7th International Advance Computing Conference (IACC) (pp. 330-332). IEEE.

[8] Sinha, N., Pujitha, K. E., \& Alex, J. S. R. (2015, January). Xively based sensing and monitoring system for IoT. In 2015 International Conference on Computer Communication and Informatics (ICCCI) (pp. 1-6). IEEE.

[9] Li, X., Lu, R., Liang, X., Shen, X., Chen, J., \& Lin, X. (2011). Smart community: an internet of things application. IEEE Communications magazine, 49(11), 68-75.

[10] Benammar, M., Abdaoui, A., Ahmad, S. H., Touati, F., \& Kadri, A. (2018). A modular IoT platform for real-time indoor air quality monitoring. Sensors, 18(2), 581. 